\title{
Development of appetizer (spiced squash) from mulberry (Morus alba L.) and its quality evaluation during storage
}

\author{
Hamid* and N. S. Thakur \\ -173230 (HP), INDIA \\ *Corresponding author. E-mail: Hamidsonu2014@gmail.com \\ Received: January 10, 2017; Revised received: May 4, 2017; Accepted: October 13, 2017
}

Department of Food Science and Technology, Dr YS Parmar University of Horticulture and Forestry, Nauni, Solan

\begin{abstract}
The present investigations were conducted to develop a commercial appetizer (spiced squash) from mulberry and its quality evaluation during storage. Different combinations of juice $(20,25,30,35$ and $40 \%)$ and TSS (40 and $45^{\circ} \mathrm{B}$ ) were tried to standardize proper combination for appetizer. Out of 10 different treatment combinations of juice and TSS tried, appetizer recipe $\left(A_{5}\right)$ prepared with $40 \%$ juice, $40{ }^{\circ} \mathrm{B}$ TSS and $1.30 \%$ acid was found to be best on the basis of sensory and some physico-chemical characteristics of the product. The appetizer prepared by following the best selected recipe was packed in glass and PET (polyethylene terephthalate) bottles and stored for six months under ambient $\left(20-25^{\circ} \mathrm{C}\right)$ and refrigerated temperature conditions (4-7 $\left.{ }^{\circ} \mathrm{C}\right)$. Overall effect shows that various quality characteristics like TSS, apparent viscosity, reducing sugars, and total sugars of appetizer increased from 40.00 to $40.63,185.08$ to $193.75,28.37$ to $31.80,37.12$ to 38.53 and other chemical characteristics like acidity, ascorbic acid, anthocyanins, total phenols and sensory characteristics scores of colour, body, taste, aroma, overall acceptability score decreased from 1.30 to $1.21,5.18$ to $3.75,8.60$ to $5.75,58.22$ to $49.23,8.15$ to $7.52,8.00$ to $7.30,8.20$ to $7.26,8.00$ to $7.03,8.10$ to 7.15 , respectively during storage. However, quality of the product was retained better in glass than PET bottles under refrigerated condition as compare to ambient storage condition.
\end{abstract}

Keywords: Appetizer, Mulberry, Morus alba, packaging material, Storage

\section{INTRODUCTION}

Mulberry (Morus alba L.) a wild fruit is known as shahtut, chinni and tut in Himachal Pradesh (HP). It belongs to genera Morus in family moraceae. Morus genus has about 68 species of trees and shrubs throughout the world. This genus is widely distributed in Asia, Africa, Europe, South and North America. It is also widely found in hilly areas of Himalayas up to 3300 m elevation (Zafar et al., 2013). Among various Morus species Morus alba L. has been cultivated widely in Asia especially in China, Japan and India for rearing silkworms besides fruit purpose (Ercisli and Orhan, 2007). In India, Morus alba is widely distributed in Jammu and Kashmir, UP, Karnataka, Tamilnadu, West Bengal, Kerala and to a lesser extent in HP and found in an elevation between 400 to $2000 \mathrm{~m}$ above mean sea level (Kaur and Sharma, 2004). In India the mulberry fruit trees are generally grown for rearing silkworms and to a small extent for its fruits. Fruits of this species are long, ovoid or cylindrical, which are variable in colour like white, pink or purple to black. The fruits of Morus alba are rich source of antioxidants including ascorbic acid (vitamin C), anthocyanins and polyphenols (Lochynska, 2015), besides its high nutrition and value for traditional medicine. Its fruits contain essential fatty acids especially linoleic, stearic and oleic acids in seeds $(0.3-0.5 \%)$, vitamin C as ascorbic acid (11.0-12.5 mg/100 g), polyphenols (181 mg QE/100 g), carbohydrates (7.8-9.0\%), fibre $(0.9-1.3 \%)$, minerals $(0.8-1.0 \%)$, riboflavin $(165-179$ $\mu \mathrm{g} / 100 \mathrm{~g})$, carotene $(0.16-0.17 \%)$, anthocyanins $(13.70$ $-205.70 \mathrm{mg} / 100 \mathrm{~g})$ and nicotinic $\operatorname{acid}(0.7-0.8 \mathrm{mg} / 100$ g)(Ercisli and Orhan, 2007; Bae, and Suh, 2007; Singhal et al., 2010). Mulberry juice is full of antiaging properties and enriches the blood, protecting liver from damage, calms the nerves, balances internal secretions and enhances immunity (Yadav et al., 2014). Mulberry fruits can be used as a worming agent, as a remedy for dysentery and as a laxative, anthelmintic, expectorant, hypoglycaemic and emetic (Ercisli and Orhan, 2007).The small edible fruits with attractive colour are sweet which can be consumed fresh and can also be processed into various fruit products. Very less work on processing of this fruit has been reported so far. So, being a rich source of antioxidants especially phenols, this fruit can be exploited for the development of some beverages specially appetizer. The literal meaning of appetizer is one which creates appetite. This beverage is named appetizer because the spices and herbs extracts added to it for producing appetizing effect. Thus, the present studies were under taken with the objective to develop appetizer from this underutilized fruit and to study its stor- 
age life.

\section{MATERIALS AND METHODS}

The mature fruits of Morus alba procured from Bela area of Hamirpur district of Himachal Pradesh in the month of April during 2015 and used for various physico-chemical analysis and juice extraction. The juice from the mulberry fruits was easily extracted by using hydraulic press machine. According to FSSAI (2011), fruit squash should have minimum percentage of TSS as $40{ }^{\circ} \mathrm{B}$ and fruit juice as 25 per cent in final product which is diluted before consumption. So, we tried to standardize the recipe (Fig. 1) of mulberry appetizer by mixing in different concentrations of its juice with sugar syrup as given in Table 1. A constant amount of spice extract ( $100 \mathrm{ml} /$ litre appetizer) was also added to all the combinations. Spice extract was prepared according to Thakur et al. (2016) by boiling a ground mixture of pre-determined quantities of spices like cardamom (1 g), cumin (2.5 g), black pepper (2.5 g), common salt $(5 \mathrm{~g})$ in $200 \mathrm{ml}$ of water, then straining and mixing the extract with mint extract $(10 \mathrm{ml})$ and ginger juice $(15 \mathrm{ml})$. To get the desirable concentration of acid $(1.30 \%)$ in appetizer, citric acid was added in different combinations. Sodium benzoate $(600 \mathrm{ppm})$ was added at the end of product preparation of appetizer in all the treatment combinations. The synthetic colour carmosine at the rate of 0.0025 per cent was added in all treatment combinations.

Packaging and storage: The appetizer prepared by following the best selected recipe was packed in presterilised glass and PET bottles (700 ml capacity). All the packed products were properly labelled and stored in ambient $\left(20-25^{\circ} \mathrm{C}\right)$ and low temperature $\left(4-7^{\circ} \mathrm{C}\right)$ conditions for six months. The physico-chemical and sensory characteristics of all the products were estimated at zero, three and six months of storage.

Physico-chemical analysis and sensory evaluation: The colour (Red and Yellow) of appetizer in terms of different tintometer colour units (TCU) was observed with Tintometer (Lovibond Tintometer Model-E). Average fruit size, weight, volume, specific gravity and juice percentage were estimated according to methods of Ranganna (1997). Moisture, total solids, TSS, reducing sugars, total sugars, titratable acidity and anthocyanins of fruits and prepared products were determined according to method described by Ranganna (1997) and AOAC (1990). The pH of the samples was determined by using a digital $\mathrm{pH}$ meter (CRISON Instrument, Ltd, Spain). Total phenols content (mg/100 g) was determined by Folin-Ciocalteu procedure given by Singelton and Rossi (1965). Nine points hedonic rating test was followed for conducting the sensory evaluation of mulberry appetizer (Amerine et al., 1965). The panel of ten judges were selected to evaluate the product for sensory parameters such as colour, body, taste, aroma and overall acceptability.

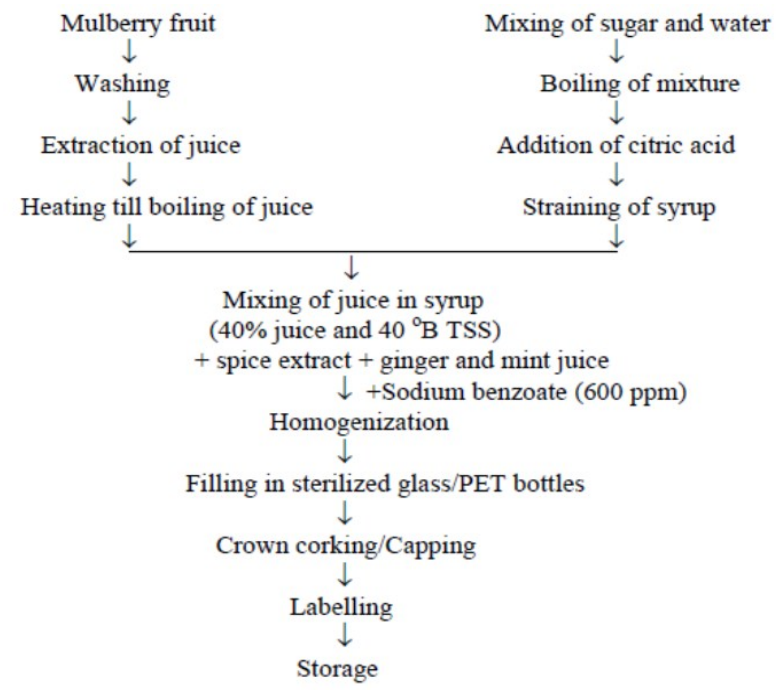

Fig. 1. Unit operations for the preparation of mulberry appetizer.

Statistical analysis: Data on physico-chemical characteristics of mulberry fruits were analysed as mean of replications and standard deviation. While data on physico-chemical characteristics of appetizer was analysed by Completely Randomized Design (CRD) before and during storage by preparing ANOVA table, whereas, data pertaining to the sensory evaluation were analyzed by using Randomized Block Design (RBD) as described by Mahony (1985). The experiments on recipe standardization and for storage studies were replicated three times.

\section{RESULTS AND DISCUSSION}

Physico-chemical characteristics of mulberry fruit: Data of physical characteristics of mulberry fruit indicates that mean length and diameter of fruit found to be $17.58 \pm 1.32$ and $11.16 \pm 1.17 \mathrm{~mm}$, respectively. Further, mean weight and volume of fruit were recorded as $1.17 \pm 0.15 \mathrm{~g}$ and $0.97 \pm 1.52 \mathrm{ml}$, respectively. The mean specific gravity of fruit was found to be 1.02 \pm 0.03 . The mean juice content was found to be 58.45 per cent. Nearby results for these parameters of mulberry fruit have also been reported by Gungor and Sengul (2008) and Singhal et al. (2010).The average moisture and total solids content of fruit was found to be $81.68 \pm 0.64$ and $18.32 \pm 0.64$ per cent, respectively. The mean TSS content of mulberry fruit was found to be $14.15 \pm 1.05{ }^{\circ} \mathrm{B}$ and titratable acidity and $\mathrm{pH}$ of the same were recorded as $0.44 \pm 0.12$ per cent (as \% citric acid) and $4.22 \pm 0.01$, respectively. The similar findings of these parameters have been also observed by Ercisli and Orhan (2007). The ascorbic acid content was found to be $14.07 \pm 0.79 \mathrm{mg} / 100 \mathrm{~g}$ of fruit. The total sugars content of fruit was observed as $11.84 \pm$ 0.42 per cent out of which the reducing sugars content was found to be $9.10 \pm 0.16$ per cent. Present results of these parameters are supported by Gungor and Sengul 
Table 1. Treatment detail of appetizer.

\begin{tabular}{lllllllllll}
\hline Treatment & $\mathbf{A}_{\mathbf{1}}$ & $\mathbf{A}_{\mathbf{2}}$ & $\mathbf{A}_{\mathbf{3}}$ & $\mathbf{A}_{\mathbf{4}}$ & $\mathbf{A}_{\mathbf{5}}$ & $\mathbf{A}_{\mathbf{6}}$ & $\mathbf{A}_{\mathbf{7}}$ & $\mathbf{A}_{\mathbf{8}}$ & $\mathbf{A}_{\mathbf{9}}$ & $\mathbf{A}_{\mathbf{1 0}}$ \\
\hline Juice (\%) & 20 & 25 & 30 & 35 & 40 & 20 & 25 & 30 & 35 & 40 \\
TSS ( $\left.{ }^{\circ} \mathrm{B}\right)$ & 40 & 40 & 40 & 40 & 40 & 45 & 45 & 45 & 45 & 45 \\
\hline
\end{tabular}

Table 2. Physico-chemical characteristics of different recipes of mulberry appetizer (mean \pm S.D.

\begin{tabular}{|c|c|c|c|c|c|}
\hline \multirow{3}{*}{ Treatments (A) } & \multicolumn{5}{|c|}{ Physico-chemical characteristics } \\
\hline & \multicolumn{2}{|c|}{ Colour (TCU) } & \multirow{2}{*}{$\begin{array}{c}\text { Anthocyanins } \\
(\mathrm{mg} / 100 \mathrm{ml})\end{array}$} & \multirow{2}{*}{$\begin{array}{c}\text { Total phenols } \\
\text { (mg/100 g) }\end{array}$} & \multirow{2}{*}{$\begin{array}{c}\text { Ascorbic acid } \\
(\mathrm{mg} / 100 \mathrm{ml})\end{array}$} \\
\hline & $\mathbf{R}$ & $\mathbf{Y}$ & & & \\
\hline $\mathrm{A}_{1}$ & $21.60 \pm 0.02$ & $3.75 \pm 0.02$ & $4.15 \pm 0.04$ & $31.28 \pm 0.06$ & $2.78 \pm 0.02$ \\
\hline $\mathrm{A}_{2}$ & $21.84 \pm 0.02$ & $3.50 \pm 0.01$ & $5.42 \pm 0.02$ & $37.42 \pm 0.08$ & $3.20 \pm 0.02$ \\
\hline $\mathrm{A}_{3}$ & $21.96 \pm 0.02$ & $3.32 \pm 0.03$ & $6.32 \pm 0.05$ & $45.11 \pm 0.09$ & $3.82 \pm 0.03$ \\
\hline $\mathrm{A}_{4}$ & $22.14 \pm 0.02$ & $3.18 \pm 0.01$ & $7.36 \pm 0.04$ & $52.95 \pm 0.05$ & $4.65 \pm 0.01$ \\
\hline $\mathrm{A}_{5}$ & $22.30 \pm 0.05$ & $3.03 \pm 0.02$ & $8.60 \pm 0.04$ & $58.22 \pm 0.06$ & $5.18 \pm 0.02$ \\
\hline $\mathrm{A}_{6}$ & $21.68 \pm 0.04$ & $3.70 \pm 0.03$ & $4.15 \pm 0.04$ & $31.34 \pm 0.05$ & $2.80 \pm 0.01$ \\
\hline $\mathrm{A}_{7}$ & $21.95 \pm 0.02$ & $3.44 \pm 0.02$ & $5.44 \pm 0.06$ & $37.48 \pm 0.04$ & $3.21 \pm 0.03$ \\
\hline $\mathrm{A}_{8}$ & $22.10 \pm 0.05$ & $3.27 \pm 0.01$ & $6.40 \pm 0.02$ & $45.14 \pm 0.05$ & $4.07 \pm 0.01$ \\
\hline $\mathrm{A}_{9}$ & $22.25 \pm 0.02$ & $3.15 \pm 0.02$ & $7.32 \pm 0.05$ & $52.86 \pm 0.03$ & $4.71 \pm 0.02$ \\
\hline $\mathrm{A}_{10}$ & $22.40 \pm 0.01$ & $3.10 \pm 0.01$ & $8.60 \pm 0.06$ & $58.18 \pm 0.06$ & $5.16 \pm 0.14$ \\
\hline $\mathrm{CD}_{0.05}$ & 0.05 & 0.03 & 0.07 & 0.10 & 0.08 \\
\hline
\end{tabular}

Table 3. Sensory characteristics (score) of different recipes of mulberry appetizer.

\begin{tabular}{lccccc}
\hline Treatment (A) & Colour & Body & Taste & Aroma & Overall acceptability \\
\hline $\mathrm{A}_{1}$ & 7.80 & 6.00 & 6.20 & 6.23 & 6.37 \\
$\mathrm{~A}_{2}$ & 7.70 & 6.50 & 6.00 & 6.50 & 6.67 \\
$\mathrm{~A}_{3}$ & 8.00 & 6.80 & 6.40 & 7.20 & 7.10 \\
$\mathrm{~A}_{4}$ & 8.20 & 7.00 & 7.50 & 7.80 & 8.70 \\
$\mathrm{~A}_{5}$ & 8.15 & 8.00 & 8.20 & 8.00 & 6.40 \\
$\mathrm{~A}_{6}$ & 8.00 & 5.50 & 6.00 & 6.10 & 6.57 \\
$\mathrm{~A}_{7}$ & 7.50 & 5.80 & 6.20 & 6.80 & 7.40 \\
$\mathrm{~A}_{8}$ & 8.20 & 6.50 & 7.50 & 7.40 & 7.30 \\
$\mathrm{~A}_{9}$ & 7.43 & 7.00 & 7.20 & 7.90 & 7.05 \\
$\mathrm{~A}_{10}$ & 7.00 & 6.60 & 6.20 & 8.50 & 0.29 \\
$\mathrm{CD}_{0.05}$ & 0.28 & 0.25 & 0.35 & 0.32 & \\
\hline
\end{tabular}

(2008). Crude fibre content of the mulberry fruit was found to be $0.93 \pm 0.12$ per cent. Whereas, the higher amounts of anthocyanins and total phenolic contents in the fruit were observed as $22.17 \pm 1.12 \mathrm{mg} / 100 \mathrm{~g}$ and $153.30 \pm 1.64 \mathrm{mg} / 100 \mathrm{~g}$, respectively. These findings are in conformity with the reported results by Singhal et al. (2010) for fibre, Bae and Suh (2007) for anthocyanins, Ercisli and Orhan (2007) for phenolic content.

Standardization of recipe for the preparation of mulberry appetizer: Data on physico-chemical characteristics of mulberry appetizer was given in Table 2 . TSS of first five recipes was maintained $40{ }^{\circ} \mathrm{B}$ and for rest they were kept at $45{ }^{\circ} \mathrm{B}$, during the preparation of the product to assess the variability in sensory liking behaviour of individual treatment by the sensory panelists. With the increase in juice content in different recipes a significant effect on physico-chemical characteristics of mulberry appetizer recipes has been observed. Data presented in Table 2 show that recipe $A_{1}$ and $\mathrm{A}_{6}$ contain less content of anthocyanins, total phenols and ascorbic acid, it might be due to less percentage of juice used as compared to other recipes like $\mathrm{A}_{5}$ and $\mathrm{A}_{10}$, which contains higher content of anthocyanins, total phenols and ascorbic acid, because of higher percentage of juice used in these recipes. The change in juice content has also affected the colour units of different recipes of appetizer. These findings are in conformity with the earlier reported results by Thakur et al. (2016) on box myrtle appetizer and Jain et al. (2016) in which they reported increase in ascorbic acid content of aonla squash with the increase in juice content in different treatments. Data on sensory characteristics of different recipes of mulberry appetizer as mentioned in Table 3 indicate that the recipe with 40 per cent juice and $40{ }^{\circ} \mathrm{B}$ TSS $\left(\mathrm{A}_{5}\right)$ was the best on the basis of sensory and some physico-chemical characteristics of appetizer. The higher overall acceptability scores for recipe $\mathrm{A}_{5}$ might be due to better combination of juice-acid-spices-syrup blend, higher juice content, appealing colour, aroma and body as compared to other recipes. Our results are in accordance with the findings of Jain et al. (2016) on aonla squash in which they reported that overall acceptability scores of the beverage increased with the increase in proportion of juice content from 25 to 40 per cent.

\section{Storage of mulberry appetizer}

\section{Physico-chemical characteristics}

Colour: There was a significant decrease in red (R) and yellow (Y) TCU (Fig. 2a and 2b) during storage of mulberry appetizer. More decrease in red and yellow 


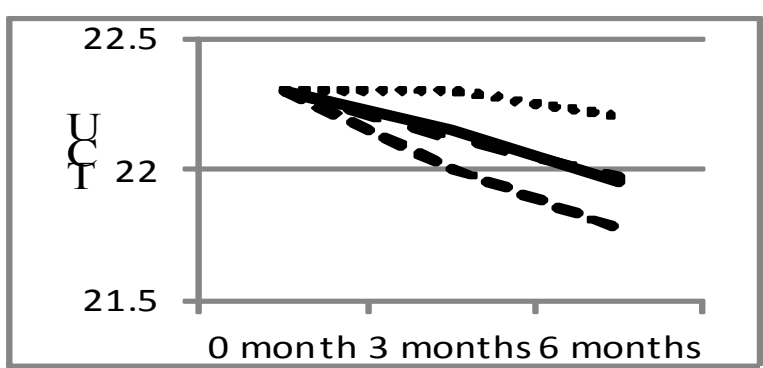

a. Red TCU

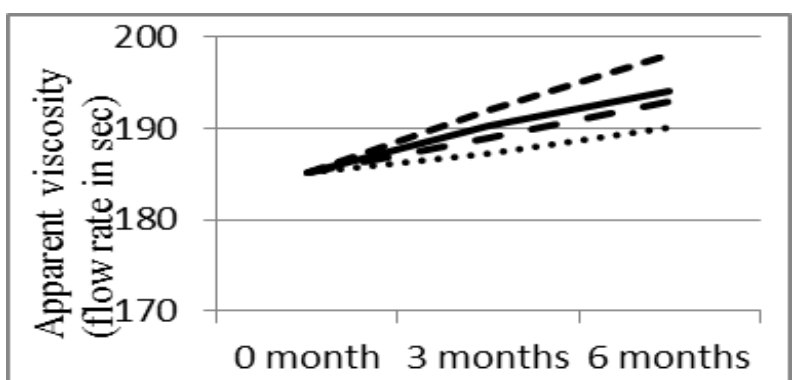

c. Apparent viscosity (flow rate $\mathrm{n}$ seconds)

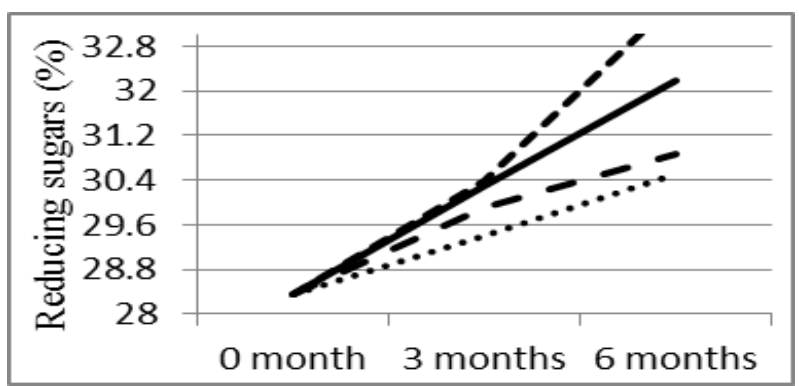

e. Reducing sugars (\%)

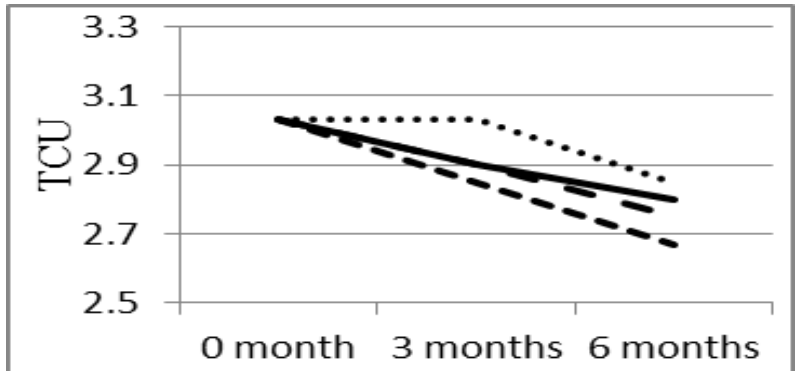

b. Yellow TCU

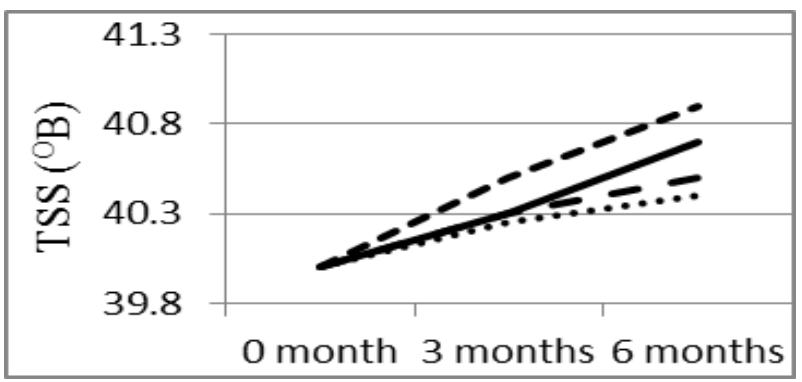

d. $\operatorname{TSS}\left({ }^{\circ} \mathrm{B}\right)$

Fig. 2. Effect of storage on physico-chemical characteristics of mulberry appetizer.

colour units of appetizer was recorded under ambient storage conditions $\left(20-25{ }^{\circ} \mathrm{C}\right)$ as compared to refrigerated conditions. Decrease in colour units during storage might be due to degradation of anthocyanin pigments (Thakur et al., 2016). The reason for less decrease in colour units of appetizer during storage might be due to stable nature of synthetic colour towards heat and light. Similar trend of decrease in red and yellow TCU has been reported by Suryawanshi et al. (2008) in pomegranate juice.

Apparent viscosity: Apparent viscosity of mulberry appetizer increased significantly (Fig. 2c) during the storage period. Increase in apparent viscosity may be due to increase in TSS and soluble sugar which increased strain and shearing rate. As the flow index decreases it helps to develop pseudo plasticity and increased the apparent viscosity of the product (Bal et al., 2014). This increase in apparent viscosity was observed more in appetizer stored under ambient temperature conditions as compare to refrigerated storage conditions. Similar results have been reported by Khurdiya and Lotha (1994) for kinnow mandarin juices.
TSS: The TSS content of appetizer increased slightly during storage (Fig. 2d) and this increase in TSS during storage might be due to hydrolysis of polysaccharides into simple sugars (Kesharwani et al., 2015). More increase in TSS was found in appetizer stored under ambient conditions (Increased from 40 to 40.70 and $40.90{ }^{\circ} \mathrm{B}$ in both glass and PET) as compared to refrigerated storage conditions (Increased from 40 to 40.40 and $40.50{ }^{\circ} \mathrm{B}$ in both glass and PET) and this might be due to the faster rate of reaction because of high temperature in ambient conditions. Sharma et al. (2002) in plum appetizer and Selvamuthukumaran and Khanum (2013) in spiced seabuckthorn mix fruit squash have also reported slight increase in TSS of the respective products due to conversion of polysaccharides into simple sugars during storage.

Reducing sugar: Reducing sugars of appetizer showed (Fig. 2e) a significant increase in storage which was comparatively less in refrigerated storage conditions than in ambient conditions. More increase in reducing sugars was found in appetizer stored under ambient conditions (Increased from 28.37 to 32.18 and $33.65 \%$ in both glass and PET) as compared to refrigerated 


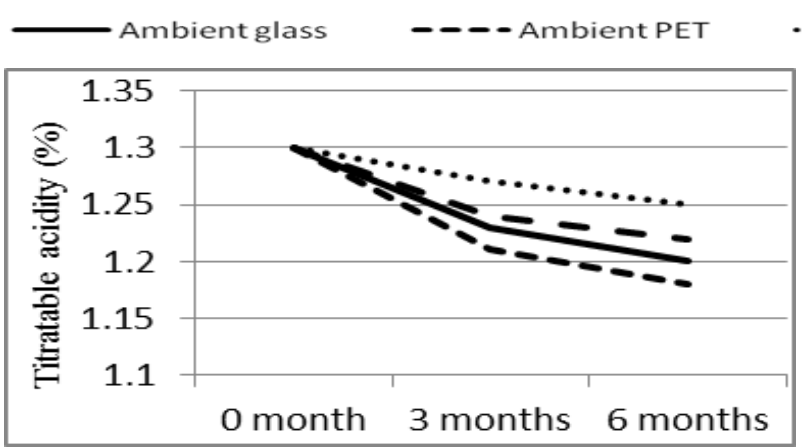

a. Titratable acidity $(\%)$

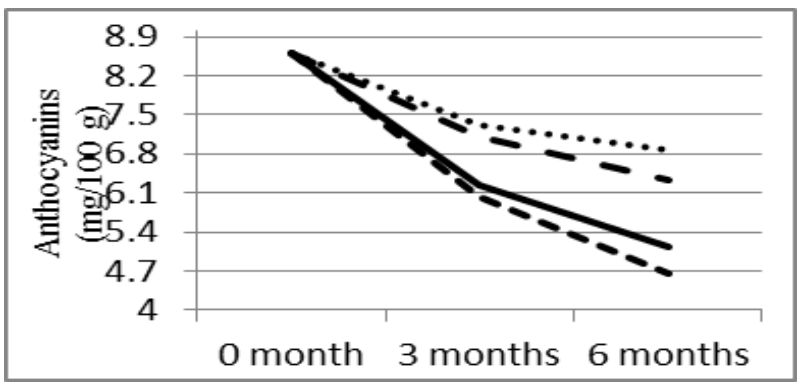

c. Anthocyanins $(\mathrm{mg} / 100 \mathrm{~g})$
Refrigerated glass $\quad \ldots \quad-$ Refrigerated PET

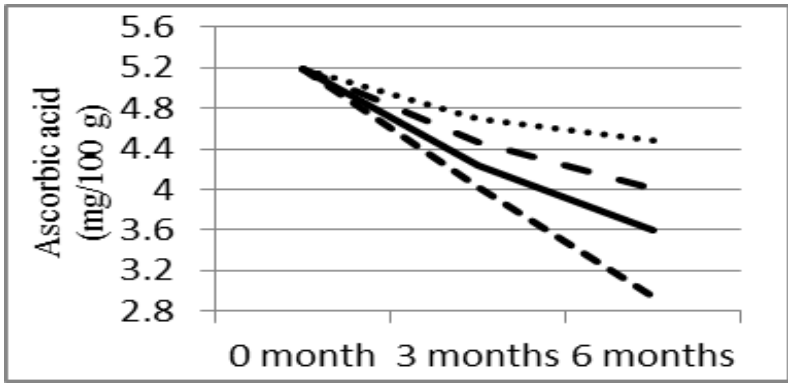

b. Ascorbic acid (mg/100 g)

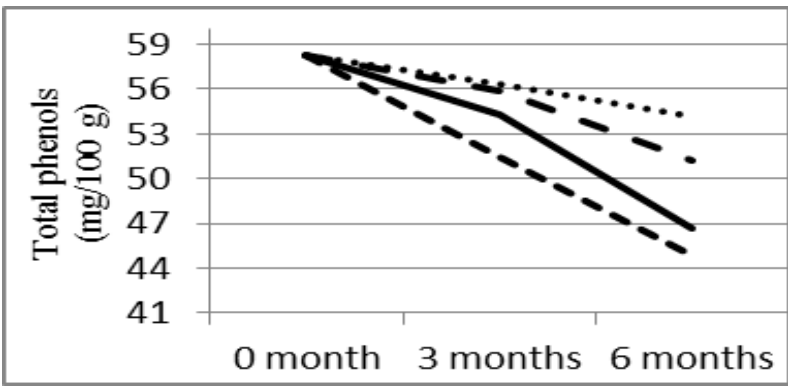

d. Total phenols $(\mathrm{mg} / 100 \mathrm{~g})$

Fig. 3. Effect of storage on physico-chemical characteristics of mulberry appetizer.

storage conditions (Increased from 28.37 to 30.52 and $30.87 \%$ in both glass and PET). Increase in sugars during storage might be attributed to the hydrolysis of starch into sugars (Heikal et al., 1964) and higher increase might be due to the faster rate of reactions because of high temperature in ambient conditions. Similar trend of increase in sugars have been reported by Sharma et al. (2002) in plum appetizer and Kaushal (2004) in seabuckthorn appetizer. The more increase in sugars recorded in appetizer packed in PET bottle as compared to glass bottle might be due to faster rate of chemical reactions in the product packed in PET bottle as a result of difference in their thermal conductance properties.

Titratable acidity: The titratable acidity of appetizer showed slight decrease during storage (Fig. 3a) which was higher under ambient storage conditions (decreased from 1.30 to 1.20 and $1.18 \%$ in both glass
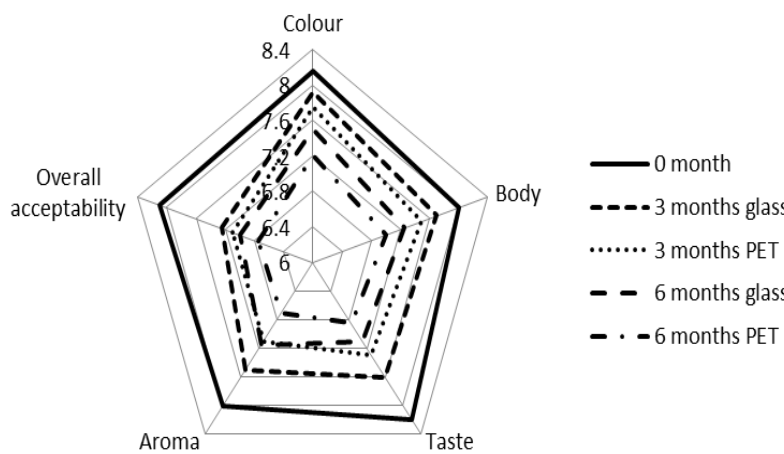

Fig. 4. Effect of storage and packaging on sensory characteristics of mulberry appetizer stored under ambient conditions. and PET) than refrigerated conditions (decreased from 1.30 to 1.25 and $1.22 \%$ in both glass and PET). The decrease in titratable acidity of appetizer could be attributed to copolymerization of organic acids (Selvamuthukumaran and Khanum, 2013). Our results are in conformity with the findings of Deka et al. (2004) in lime-aonla appetizer and Selvamuthukumaran and Khanum (2013) in spiced seabuckthorn mix fruit squash.

Ascorbic acid: There was a continuous decrease in ascorbic acid content of appetizer with advancement of storage period (Fig. 3b), however, decrease was significantly $(p<0.05)$ lower under refrigerated conditions (decreased from 5.18 to 4.49 and $4.00 \mathrm{mg} / 100 \mathrm{~g}$ in both glass and PET) as compared to ambient conditions (decreased from 5.18 to 3.60 and $2.94 \mathrm{mg} / 100 \mathrm{~g}$ in both glass and PET). Decrease in ascorbic acid content during storage might be due to oxidation or degra-

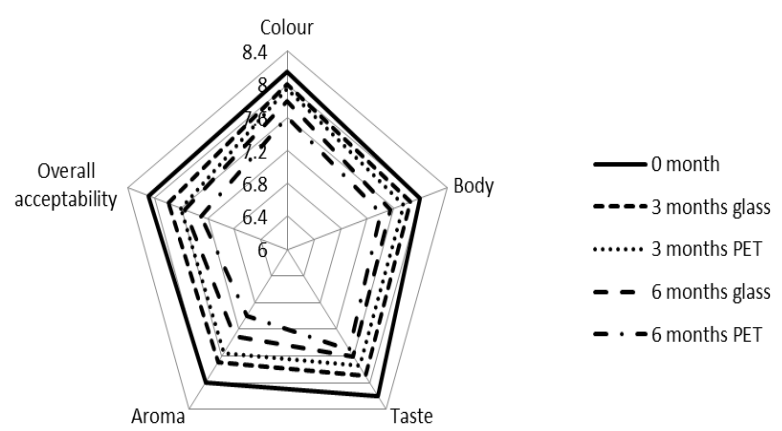

Fig. 5. Effect of storage and packaging on sensory characteristics of mulberry appetizer stored under refrigerated conditions. 
dation of ascorbic acid into dehydro-ascorbic acid, furfural and hydroxy furfural at above temperatures (Selvamuthukumaran and Khanum, 2013). Ascorbic acid is highly sensitive to heat; therefore its degradation was more in ambient conditions. Similar findings have been reported by Selvamuthukumaran and Khanum (2013) in spiced seabuckthorn mix fruit squash. Lower decrease in ascorbic acid of appetizer packed in glass bottle observed during storage might be due to the slower rate of reactions in it as glass materials absorb heat slower than PET material.

Anthocyanins: A significant $(p<0.05)$ decrease in anthocyanins content of appetizer was recorded during storage (Fig. 3c) which was more in ambient storage conditions (changes from 8.60 to 5.14 and 4.67 $\mathrm{mg} / 100 \mathrm{~g}$ in both glass and PET) than refrigerated conditions (changes from 8.60 to 6.88 and 6.32 $\mathrm{mg} / 100 \mathrm{~g}$ in both glass and PET). Loss of anthocyanins in appetizer might be due to their high susceptibility to auto oxidative degradation during storage. However, less loss of this attribute in the product might be due to slower rate of its auto oxidation in refrigerated storage conditions as compared to ambient conditions. More retention of anthocyanins of appetizer packed in glass bottle during storage might be due to the slower rate of reactions in glass bottle than PET as a result of difference in their thermal conductance properties. Our results are in accordance with the findings of Thakur et al. (2016) in box myrtle appetizer under ambient storage conditions $\left(20-25{ }^{\circ} \mathrm{C}\right)$ and refrigerated conditions $\left(4-7{ }^{\circ} \mathrm{C}\right)$.

Total Phenols: A gradual decrease in total phenols content of appetizer was observed during storage (Fig. $3 d)$ which was slower under refrigerated storage conditions (decreased from 58.22 to 54.13 and 51.22 $\mathrm{mg} / 100 \mathrm{~g}$ in both glass and PET) than ambient conditions (decreased from 58.22 to 46.73 and 44.86 $\mathrm{mg} / 100 \mathrm{~g}$ in both glass and PET) . Significant $(p<0.05)$ decrease in total phenols content during storage might be due to their involvement in the formation of polymeric compounds, complexing of phenols with protein and their subsequent precipitations as observed by Abers and Wrolstad (1979) in strawberry preserve. Similar decreasing trend intotal phenols have also been reported by Selvamuthukumaran and Khanum (2013) in spiced seabuckthorn mix fruit squash and Thakur et al. (2016) in box myrtle appetizer.

Sensory characteristics of mulberry appetizer during storage: The decrease in colour, body, taste, aroma and overall acceptability scores of appetizer was observed during storage. However, decrease in score was less in refrigerated storage conditions (Fig. 4) than ambient (Fig. 5). Decrease in colour scores during storage might be due to degradation of colour pigment (anthocyanins) and browning caused by copolymerization of organic acids of the product. As far as packaging material is concerned, there was non significant effect of packaging materials on the colour scores of appetizer. While, the possible reason for decrease in body scores might be due to the interactions between phenols and protein as well as the formation of cation complexes with pectin and phenols (Thakur et al., 2016) which led the judges to award lower scores to the product during storage. Whereas, a decrease in taste scores of appetizer with advancement of storage period might be due to the loss of sugar-acid-salt blend responsible for taste during storage. Retention of higher taste scores in refrigerated conditions might be due to the better retention of original sugar-acid-salt blend as a result of slow reaction rate contributing change in this blend. The loss of aroma scores during storage might be due to the possible loss of volatile aromatic compounds. The aroma scores of appetizer packed in glass bottle were retained better than PET bottle during storage. Retention of higher scores of aroma in refrigerated conditions might be due to the lower losses of aromatic compounds at low temperature during storage as compared to ambient conditions. Decrease in overall acceptability scores might be due to the loss in appearance, flavour compounds and uniformity of the product during storage. The similar results have also been reported earlier by Sharma et al. (2008) in plum appetizer, Selvamuthukumaran and Khanum (2013) and Kaushal et al. (2002) in seabuckthorn appetizer during storage.

\section{Conclusion}

Mulberry appetizer developed by mixing 40 per cent juice, $40{ }^{\circ} \mathrm{B}$ TSS, 1.30 per cent acidity and with a spice extract $(10 \%)$ of cardamom (1 g), cumin $(2.5 \mathrm{~g})$ black pepper $(2.5 \mathrm{~g})$, common salt $(5 \mathrm{~g})$, mint juice (1 $\%)$ and ginger juice $(1.5 \%)$ have got highest sensory characteristics scores, which could be stored safely for a period of six months under both storage conditions and also in both packaging materials like PET and glass bottles. However, maximum quality characteristics of the appetizer were retained in refrigerated storage conditions, but one can also prevent losses during storage in quality characteristics of appetizer in ambient conditions by preventing exposure to light and heat. The best quality of this beverage could be maintained in glass bottle stored under refrigerated storage conditions as compared to PET bottle. As mulberry fruit is available in Himachal Pradesh at cheapest price (15-35 rupees $/ \mathrm{kg}$ ) and have short shelf life of fresh fruits after harvest is one of the major factors that give the necessity of developing a cheap and efficient preservation process or value-addition for growers of this fruit. The cost of the appetizer prepared from mulberry fruit juice was less as comparable to the cost of the similar products in the market. Hence, mulberry fruit can be successfully utilized for the production of good quality and nutritionally enriched products with remunerative cost on commercial scale so that farmers can get addi- 
tional profit besides sericulture.

\section{ACKNOWLEDGEMENTS}

The research was conducted in Department of Food Science and Technology, Dr YS Parmar University of Horticulture and Forestry, Nauni, Solan, HP -173230, India.

\section{REFERENCES}

Abers, J.E. and Wrolstad, R.E. (1979). Causative factors of colour determination in strawberry preserves during processing and storage. Journal of Food Science and Technology, 44: 75.

Amerine, M.A. Pangborn, R.M. and Roessler, E.B. (1965). Principles of sensory evaluation of food. Academic Press, London, pp 236-268.

AOAC. (1990) Official methods of analysis of the association of official analytical chemist, Hortwits W (ed). Association of Official Analytical Chemists, Washington DC, U.S.A.

Bae, S.H. and Suh, H.J. (2007). Antioxidant activities of five different mulberry cultivars in Korea. LWT-Food Science and Technology, 40(5): 955-962.

Bal, L.M. Ahmad, T. Senapati, A.K. and Pandit, P.S. (2014). Evaluation of quality attributes during storage of guava nectar cv. Lalit from different pulp and TSS ratio. Food Processing and Technology, 5(5): 349-353.

Deka, B.C. Sethi, V. Suneja, P. and Shrivastava, V.K. (2004). Physico-chemical changes of lime aonla spiced beverage during storage. Journal of Food Science and Technology, 41(3): 329-332.

Ercisli, S. and Orhan, E. (2007). Chemical composition of white, red and black mulberry fruits. Food Chemistry, 103: $1380-1384$.

FSSAI. (2011). Food safety and standards (Food product standards and Food Additives) regulation, 2011 (Part1).pdf. pp162. http://www.fssai.gov.in/home/foodstandards/fss-regulations.html.

Gungor, N. and Sengul, M. (2008). Antioxidant activity, total phenolic content and selected physicochemical properties of white mulberry (Morus alba L.) fruits. International Journal of Food Properties, 11(1): 44-52.

Heikal, H.A. Wakeil, E.L. Foda, I.O. and Ashmawi, H. (1984). Preservation of lemon juice. Agriculture Research Review, 42: 68.

Jain, A. Gehlot, R, Siddiqui, S. and Jangra, M. R. (2016). Optimization of recipe for development of Aonla squash- A Response surface methodology approach. Journal of Applied and Natural Science, 8(3): 13411348.

Kaur, H. and Sharma, M. (2004). Flora of Sirmour (HP), Bishen Singh Mahendra Pal Singh Publication, Dehradun, pp 770 .

Kaushal, M. Sharma, P.C. Kaushal, B.B.L. and Sharma, A.K.
(2008). Standarization of methods for preparation of appetizer and ready- to- serve beverages from seabuckthorn (Hippophae sp.) berries. Journal of Food Science and Technology, 45(2): 139-142.

Kesharwani, A. Dikshit, S. N., Kumar, K. Thakur, P. and Chandel, N. 2015. Studies on physico-chemical composition of jamun and changes in chemical composition of RTS beverage during storage. The Bioscan, 7: 379-383.

Khurdiya, D.S. and Lotha, R.E. (1994). Effect of blending of kinnow mandarin juices on the quality of the blend juice and nectar. Indian Food Packer, 48: 43-45.

Lochynska, M. (2015). Energy and Nutritional Properties of the White Mulberry (Morus alba L.). Journal of Agricultural Science and Technology, 5: 709-716.

Mahony, M.O. (1985). Sensory evaluation of food: statistical methods and procedures. Marcel Dekker, New York, pp 168-169.

Ranganna, S. (1997). Handbook of analysis and quality control for fruit and vegetable products. Tata McGraw Hill, New Delhi. pp1112.

Selvamuthukumaran, M. and Khanum, F. (2013). Development of spiced seabuckthorn [Elaeagnusrhamnoides (L.) A. Nelson syn. Hippophaerhamnoides L.] mixed fruit squash. Indian Journal of Traditional Knowledge, 13(1): 132-141.

Sharma, R. Barwal, V.S. and Kaushal, B.B.L. (2002). Preparation and evaluation of spiced plum squash. Beverage and Food World, 29(3): 23-24.

Singelton, V.L. and Rossi, J.A. (1965). Colorimetry of total phenolics with phosphomolybedicphosphotungstic acid reagent. American Journal of Enology and Viticulture, 16: 144-158.

Singhal, B.K. Khan, M.A. Dhar, A. Baquel, F.M. and Bindroo B B. (2010). Approaches to industrial exploitation of mulberry fruits. Journal of Fruit and Ornamental Plant Research, 18(1): 83-89.

Suryawanshi, A.B. Kirad, K.S. Phad, G.N. and Patil, S.B. (2008). Effect of various levels of pasteurization, preservative and their combination on organoleptic evaluation on pomegranate juice stored at room temperature. The Asian Journal of Horticulture, 3(2): 429-432.

Thakur, N.S. Thakur, A. Joshi, V.K. (2016). Development of appetizer from Box myrtle (Myricanagi) and its quality evaluation during storage. International Journal of Food Fermentation Technology, 6(2): 151-161.

Yadav, P. Neelima, G. and Kumar, S. (2014). Improved shelf stability of mulberry juice by combination of preservatives. Indian Journal of Natural Products and Resources, 5(1): 62-66.

Zafar, M.S. Muhammad, F. Javed, I. Akhtar, M. Khaliq, T. Aslam, B. Waheed, A. Yasmin, R. and Zafar, H. (2013). White mulberry (Morus alba): A brief phytochemical and pharmacological evaluations account. International Journal of Agriculture and Biology, 15 (3): 612-620 